Corresponding Author:

Maylan Wulandari

maylan.wulandari@ui.ac.id

Received: 21 December 2018

Accepted: 23 January 2019

Published: 28 February 2019

Publishing services provided by

Knowledge E

(c) Maylan Wulandari and

Krisnawati Bantas. This article is

distributed under the terms of

the Creative Commons

Attribution License, which

permits unrestricted use and

redistribution provided that the

original author and source are

credited.

Selection and Peer-review under the responsibility of the 3rd IMOPH \& the 1st YSSOPH Conference Committee.

\section{Prevalence and Risk Factors of Congenital Disabilities in China, India, and Indonesia: A Systematic Review}

\section{Maylan Wulandari ${ }^{1}$ and Krisnawati Bantas ${ }^{2}$}

${ }^{1}$ Reproductive Health Sciences, Faculty of Public Health, University of Indonesia

${ }^{2}$ Epidemiology Department, Faculty of Public Health, University of Indonesia

\section{Abstract}

Congenital disabilities are one causes of mortality to the neonatal and children under five around the world. Children with congenital disabilities who survive may have a mental, physical, visual or auditory handicapped in their lifetime. Congenital disabilities generally caused by several multifactorial causes which related each other. The purpose of this research to compare prevalence and types of risk factors of congenital disabilities which most frequently researched in China, India, and Indonesia. This research is a systematic review by analyzing the relevant research journals from 2012 2017, make an assumption and conclude these journals. The prevalence of congenital disabilities in China, India, and Indonesia is varied. The highest prevalence is in Pune city, India $230,51 / 10,000$ birth. Based on the risk factors which frequently researched is mother factors: gestational age of mother $\geq 35$ years old and poor maternal education; environmental factors: mother living in urban area and living in slum area; nutrition factor: folic acid deficiency; child factors : age of fetuses when first detected, low birth weight, prematurity and baby boy; and other factor : genetics. In Indonesia, the risk factors of the congenital disabilities studied are gestational age of mother and the environmental factors where a pregnant woman lives. Identifying risk factors is useful for making intervention programs to decrease the prevalence of congenital disabilities.

Keywords: prevalence, risk factors, congenital disabilities, systematic review

\section{Introductions}

The target of Sustainable Development Goals (SDGs) proposed by the United Nations (2015) offers a great improvement from the target of the Millennium Development Goals (MDGs). One of the main target SDGs in 2030 is the third target, namely to guarantee a healthy life and encourage prosperity for everyone at all ages. One of the eight global targets to be achieved is to end the deaths of newborn babies and children that can be prevented, by lowering Neonatal Mortality at least up to 12 per 1,000 live births and Child Death Rate 25 per 1,000 live births. 
According to the data from Neonatal - Perinatal Database And Congenital disabilities Surveillance, globally congenital disabilities be the cause of child mortality at least on 3.3 million children every year. Which estimated 3.2 million of them who survive might have a mental, physical, visual or auditory handicapped lifetime. The magnitude of the social and economic costs due to the poor quality of life, lifelong disability, and reduced productivity, get social stigma and discrimination (1).

According to the World Health Statistics 2012, about 7\% child mortality around the world caused by congenital disabilities. Figure on a regional basis ranges $5 \%$ in the African region, 7\% in the region of South Asia and East Asia, and 19\% in the European region. Estimated $11 \%$ of neonatal deaths due to congenital disabilities occurred in China (2). In Indonesia, congenital disabilities became one of the causes of infants and child's deaths which contributes big enough is around $5.7 \%$ of total infant mortality and $4.8 \%$ of the total child's mortality. Neonatal mortality age 0-6 days because of congenital disabilities of $1.4 \%$. While neonatal death age of 7-28 days due to congenital disabilities increased to $19 \%$ (3)

, but the incidence of congenital disabilities reported in the world is still below the predictions. This condition could be caused by the limited capabilities of early detection by health workers, and weak surveillance and recording data of congenital disabilities. Congenital disabilities generally caused by several interrelated factors. Those factors include genetics, behavior, and environment - almost $50 \%$ of the causes of congenital disabilities of unknown cause.

The purpose of this study is to compare the prevalence and types of risk of congenital disabilities in some country in China, India, and Indonesia by using a systematic review based on the research that has been done before by other researchers. A systematic review is a research method that summarizes the results of primary research to present facts that more comprehensive and balanced. The process consists of several steps, firstly is the identification of questions of research, developed a systematic review of research protocols, determine the location of the database research results as the search area (e.g., MEDLINE, PubMed). The second is the selection of the research results that are relevant, choose the research results of quality, the extraction of data from individual studies, a synthesis of the results of the meta-analysis (if possible) or method of narrative (if not possible), and the presentation of results. The advantages of using systematic review is to get a valid and findings can be applied from some previous research on a specific phenomenon (4).

\section{Method}

\subsection{Literature Search Strategic}

A search of the relevant literature use journal database ProQuest, Oxford Journals, Google Scholar, The Lancet, and the Journal Airlangga University. The keyword that used is 'congenital disabilities,' ' prevalence of congenital disabilities,' 'risk factors of congenital disabilities,' 'congenital disabilities,' 'Asia.' In searching of data, researchers restrict the year's journals starting the year 2007 to 2017. 


\subsection{Selection of the literature}

Data obtained then analyzed using PRISMA guidelines (Preferred Reporting Items for Systematic Reviews and Meta-Analyses Statement). Researchers got 70969 results from various database journal, which is up of 207 data from Oxford Journals, 43152 data from ProQuest, 20600 data from Google Scholar, 6836 data from The Lancet, and 174 data from Journal Airlangga University. The researcher is manually selecting the data which has the title of suitability, obtained 53 journals with titles that match. Next researchers select a journal which has appropriate abstract, obtained 20 journals with the suitability of the abstract. The next step is to review the entire contents of the journal range from abstract, methods, sampling, research results and conclusions from this stage of research, retrieved eight journals that meet the criteria. For more details can be seen in Figure 1 Flow Chart Data Reduction.

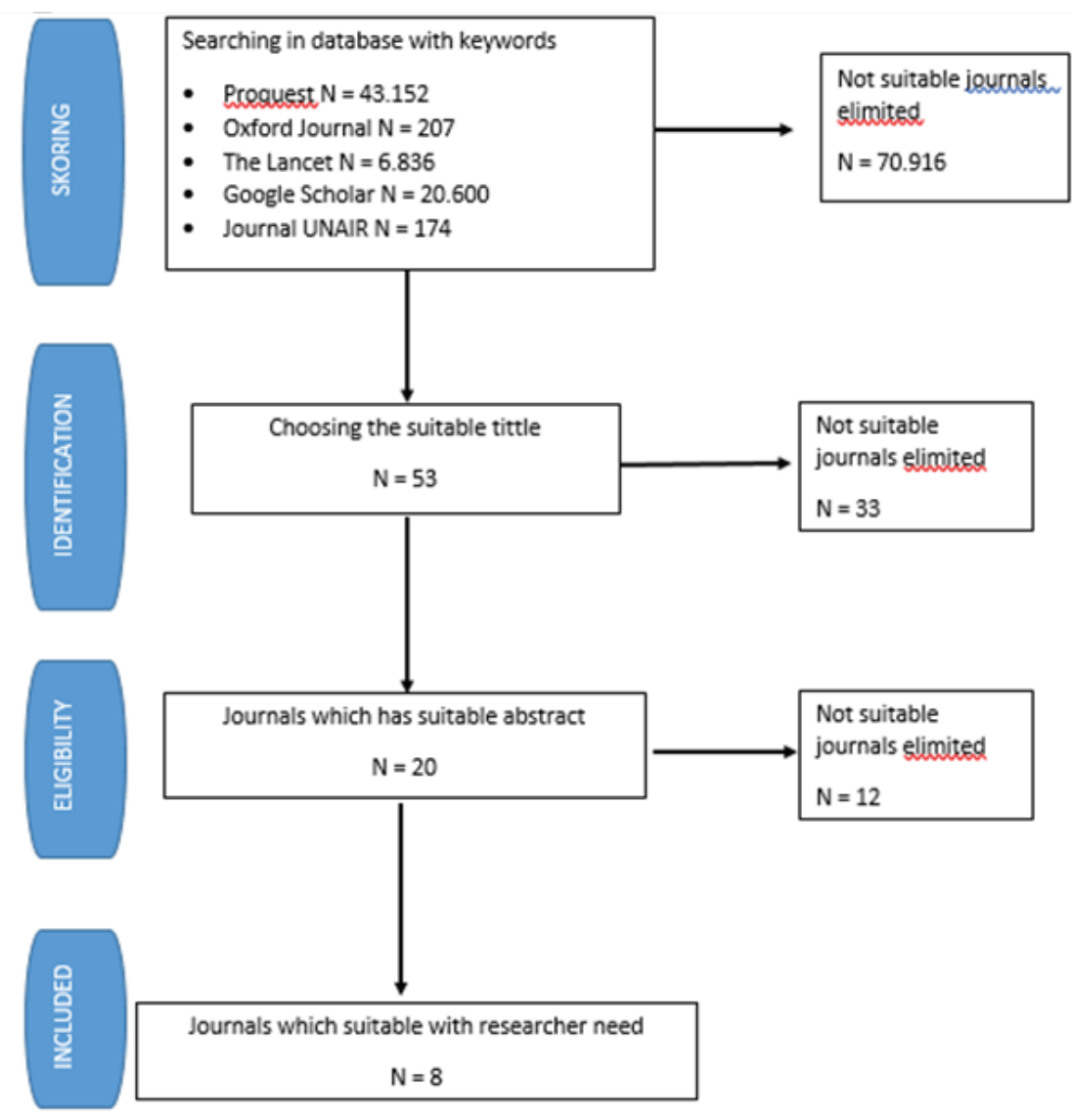

Figure 1: Flow Chart Data Reduction.

There is eight journal which will be conducted by systematic review. Eight journals and the results of the study were collected from the three countries, with the majority from China ( $n=5)$, two from India, and one of the journals from Indonesia. Such studies have a large enough sample.

\section{Result}




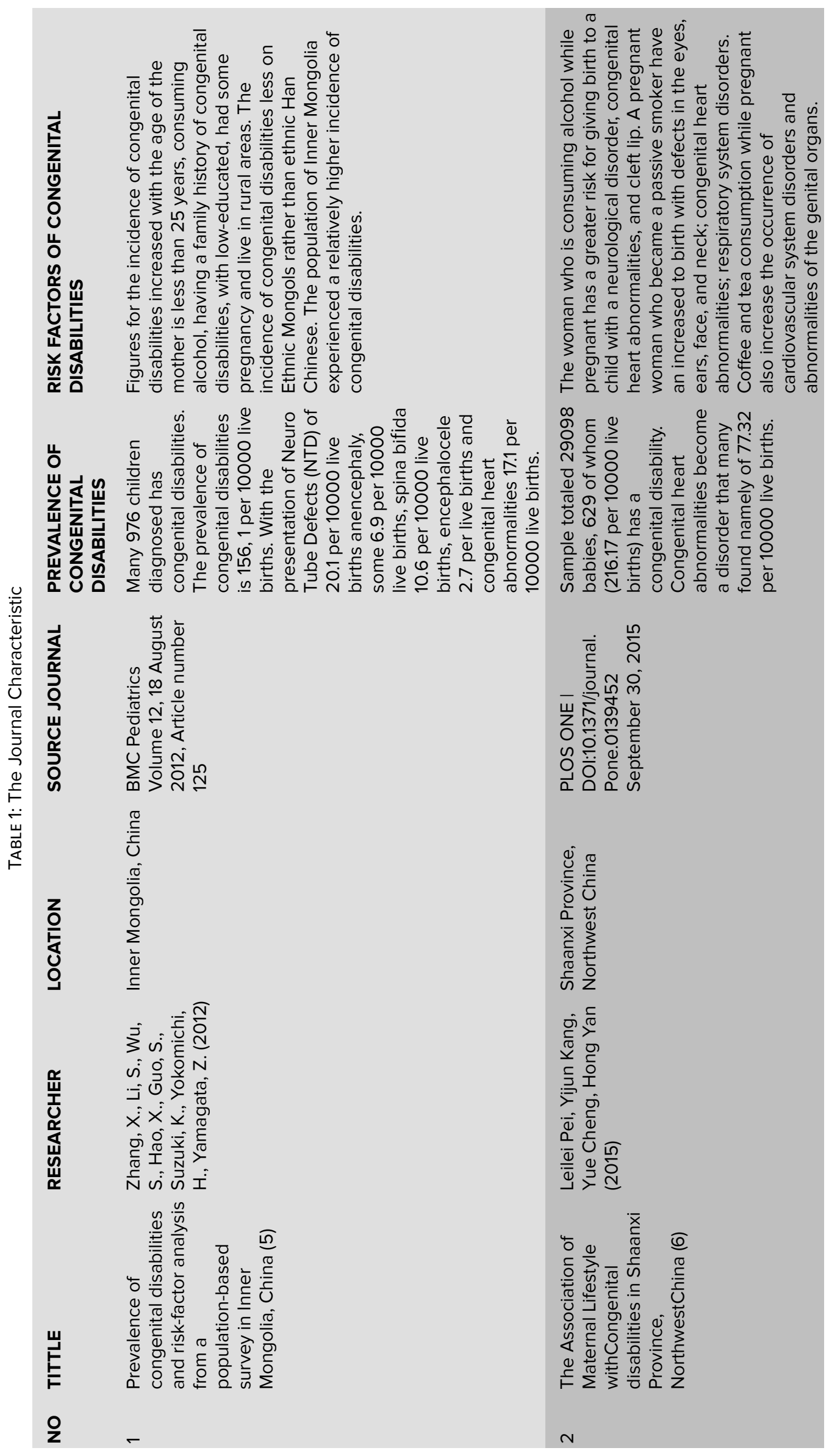




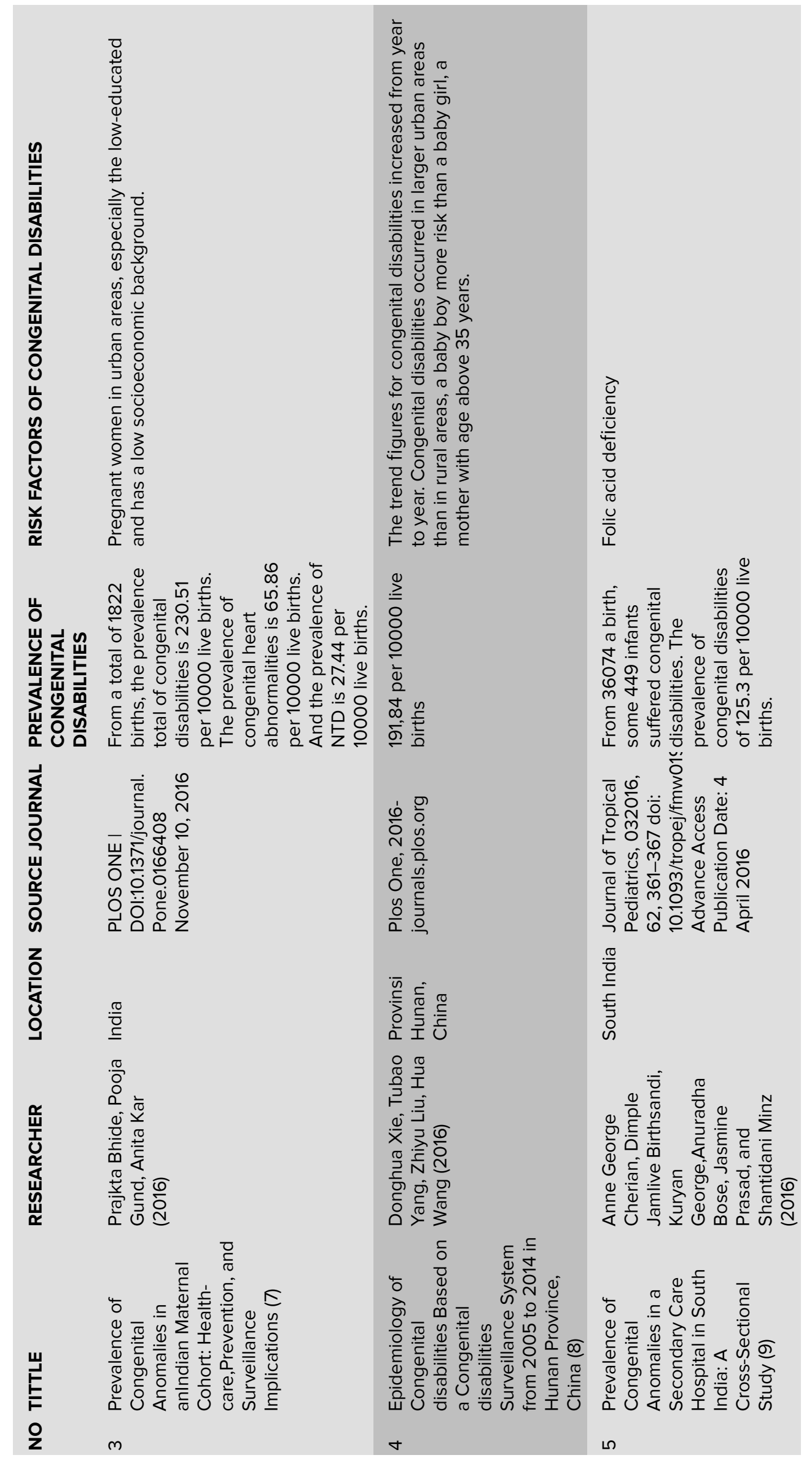




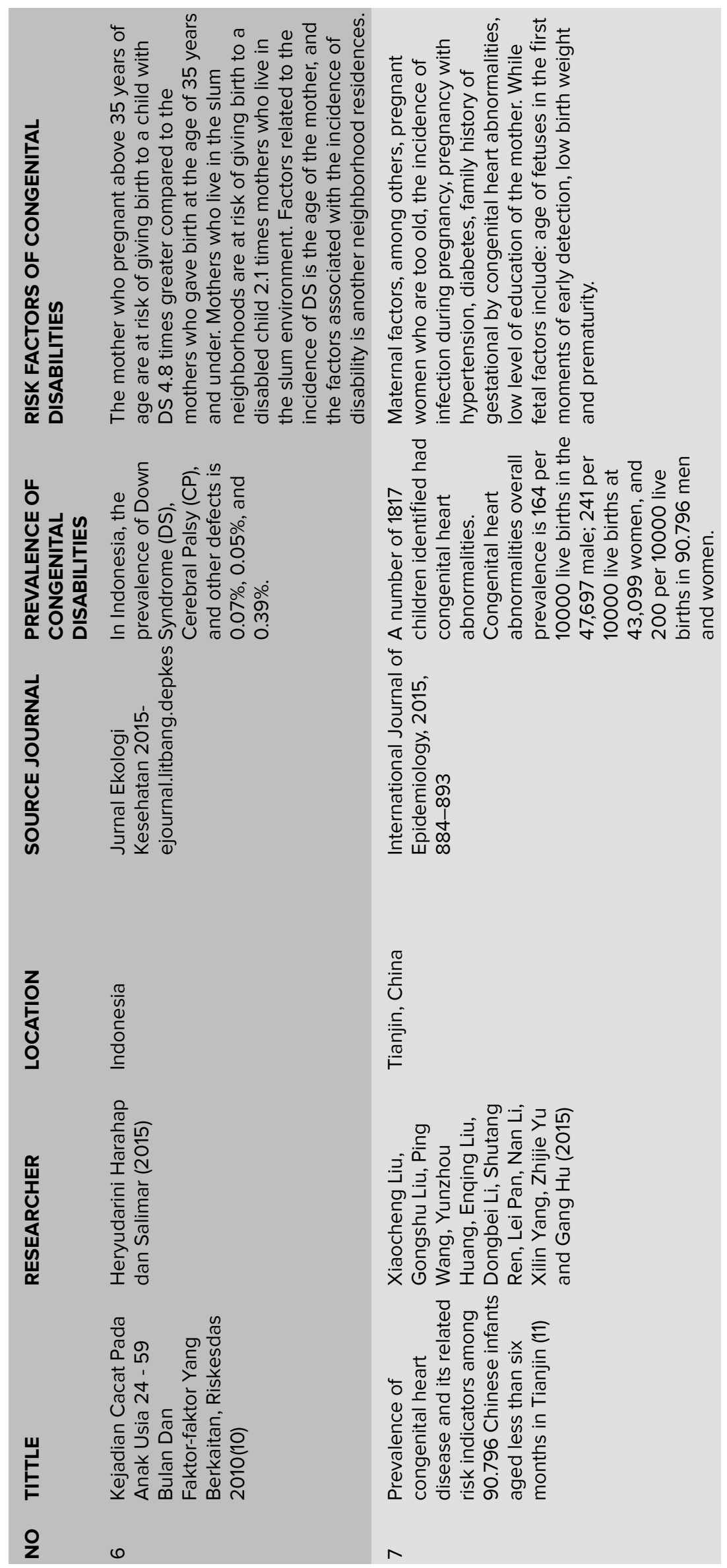




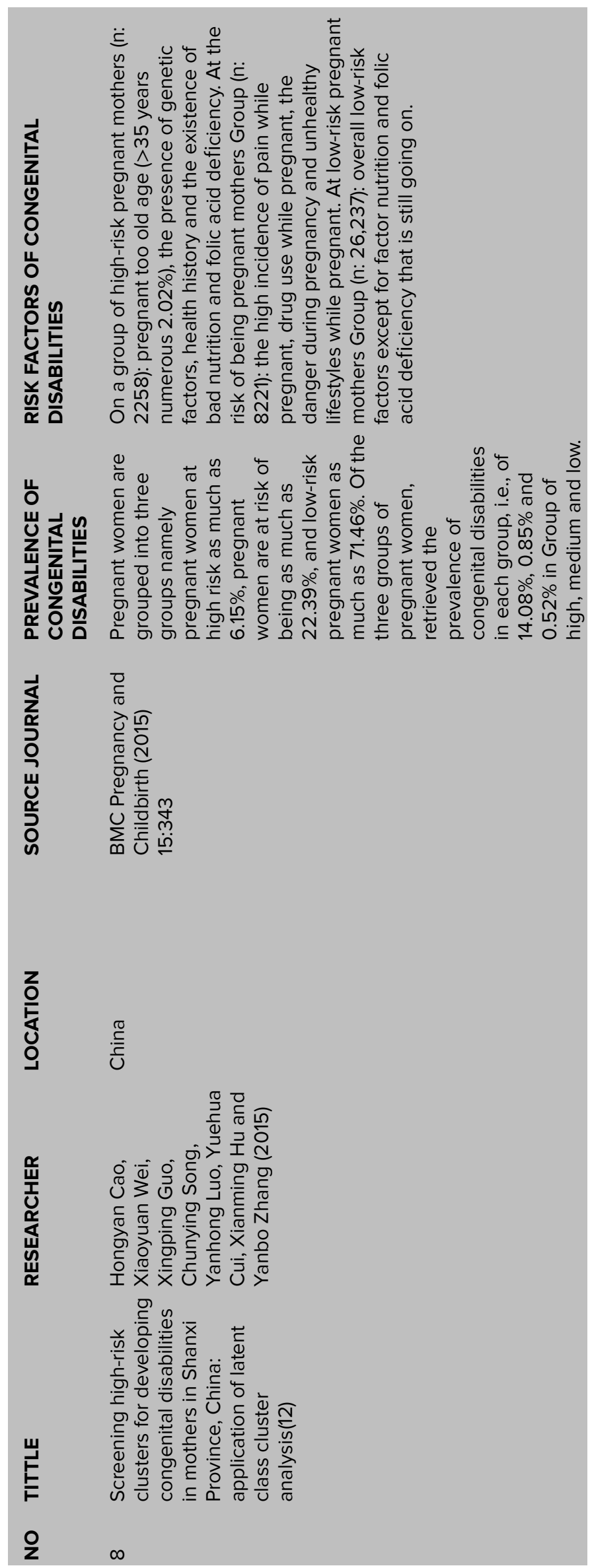




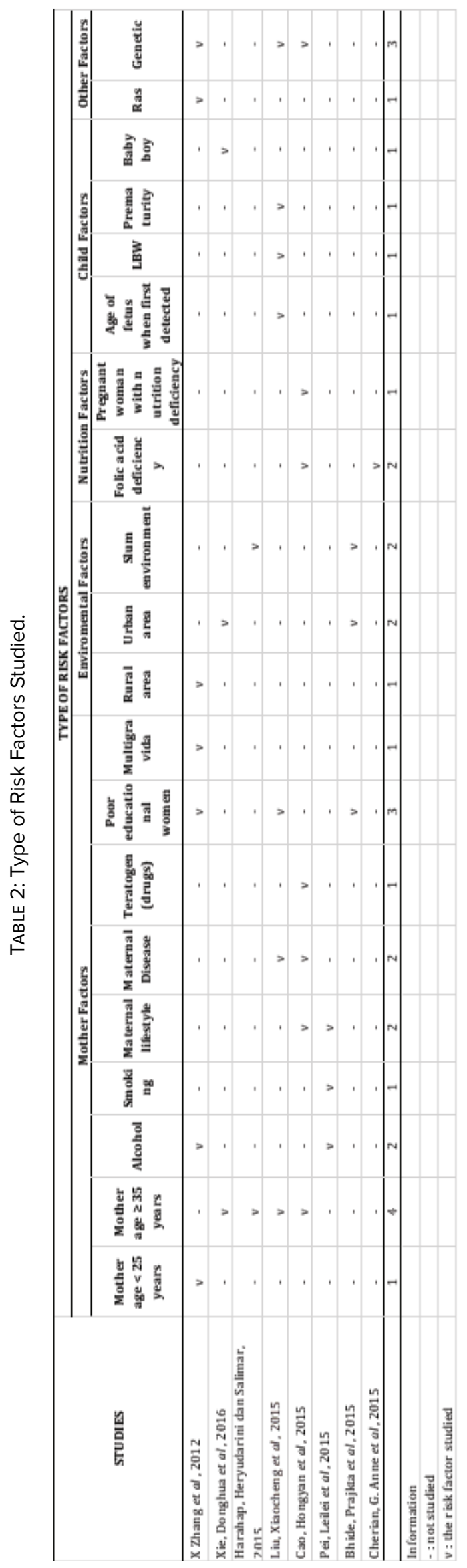




\section{Discussion}

The higher prevalence of congenital disabilities among the three countries is in India 230.51 per 10,000 live births. The study by Prajkta Bhide et al. (2016) to 2107 pregnant women until they give birth with a miscarriage, pregnancy termination, born life or stillbirth, neonatal death, and post-neonatal mortality as well. Such research is India's first cohort study to examine the prevalence and kind of congenital disabilities in babies that will be born by the pregnant mother. As for the types of congenital disabilities are congenital heart abnormalities were dominated by the prevalence of 65.86 persons per 10,000 live births and Neural Tube Defects with the prevalence of 27.44 per 10,000 live births (7).

The risk factors of congenital disabilities studied divided into four factors they are mother factors, child factors, environmental factors, nutrients factors, and the other factors. There are some aspects of the risk factors examined on each factor, for more details can be seen in table 2 . From some study, the results of which most risk factors influence on the occurrence of congenital disabilities and the most widely studied is the mother factor, in this case, the aspect of age pregnant women over 35 years old. Mother factor, on aspects of the history of the disease of the mother also examined by several researchers, because mothers who had disease while pregnant, a chance to consume some medicines teratogenic that are harmful to the fetus. Also, pregnant women who are sick can experience a deficiency of nutrients that will be influential for the formation of a fetal organ. According to the researchers, folic acid plays an important role in preventing the incidence of neural tube defects.

The other factor is the most widely studied is the aspect of the history of congenital disabilities in the family or genetic. Genetic aspects are examined by three studies. Genetic factors still play a role in the occurrence of congenital disabilities. The whole study that examines the genetic aspects is done in China. One study by Zhang et al. (2012), which examines the Inner Mongolia ethnic predisposition to having congenital disabilities. As a result, the population of Inner Mongolia experienced a relatively higher incidence of congenital disabilities than the ethnic Han Chinese (5).

The identification of the prevalence and risk factors of congenital disabilities are beneficial to determinate the intervention prevention programs of occurrence congenital disabilities. The limitation of this study is the researchers only analyzed the research in China, India, and Indonesia. It is expected the next can be researched about the risk factors and the prevalence of congenital disabilities in several countries of America, Europe, Africa, and South-East Asian countries more so that data obtained are more comprehensive and equitable. This research did not fund by any party.

\section{Conclusions}

1. The risk factors of congenital disabilities the most studied by researchers in China, India, and Indonesia are the mother factors, environmental factors, nutritional factors, and other factors. The mother factors are mother age more than 35 years and 
a low educational mother. Environmental factors are a mother living in an urban area and a mother living in a slum area. And the other factors are genetic.

2. Need for interventions in family planning programs to limit the age of high-risk pregnancy ( $\geq 35$ years). Counselling, information, and education (CIE) concerning the Movement of Healthy Living Community Programs (in Indonesia, GERMAS) to candidate pregnant women have the responsibility for maintaining health, families, and communities. When pregnant women are healthy, has a pattern of healthy living (not smoking, not drinking alcohol, eating a nutritionally balanced, and consuming vegetable fruit), and live in an environment that is free of heavy metals then the fetus they contain will be free from congenital disabilities.

3. Research using systematic review is useful to see some results of the research together, resulting obtained new findings on specific topics already researched.

\section{Acknowledgment}

I would like to thank Prof. dr. Hadi Pratomo, MPH, DrPH for his assistance to review my paper.

\section{References}

[1] WHO. Neonatal - perinatal database and congenital disabilities surveillance Neonatal - perinatal database. 2015. 19-21 p.

[2] WHO SEARO. Congenital disabilities In South-east Asia A Public Health Challenge. 2013.

[3] Badan Penelitian dan Pengembangan Kesehatan. Riset Kesehatan Dasar (RISKESDAS) 2007. Laporan Nasional 2007. 2008. 1-384 p.

[4] Siswanto S. Systematic Review Sebagai Metode Penelitian Untuk Mensistesis Hasil-Hasil Penelitian (Sebuah Pengantar). E J litbang [Internet]. 2010;(ii):329-30. Available from: http://ejournal.litbang. depkes.go.id/index.php/hsr/article/view/2766

[5] X, Zhang; S, Li; S W et al. Prevalence of congenital disabilities and risk-factor analysis from a populationbased survey in Inner Mongolia, China. BMC Pediatr. 2012;12(August):125.

[6] Pei L, Kang Y, Cheng Y, Yan H. The Association of Maternal Lifestyle with Congenital disabilities in Shaanxi Province, Northwest. PloS one J. 2015;(September 30):1-14.

[7] Bhide P, Gund P, Kar A. Prevalence of Congenital Anomalies in an Indian Maternal Cohort?: Healthcare, Prevention, and Surveillance Implications. PloS one J. 2016;(November 10):1-14.

[8] Xie, D; Yang, T; Liu Z et al. Epidemiology of Congenital disabilities Based on a Congenital disabilities Surveillance System from 2005 to 2014 in Hunan Province, China. PloS one J. 2016;

[9] Cherian G, Jamkhandi D, George K, Bose A, Prasad J, Minz S. Prevalence of Congenital Anomalies in a Secondary Care Hospital in South India?: A Cross-Sectional Study. J Trop Pediatr. 2016;(April):361-7.

[10] Harahap HS. Kejadian Cacat Pada Anak Usia 24 - 59 Bulan Dan Faktor-Faktor Yang Berkaitan, Riskesdas 2010. J Ekol Kesehat. 2015;14:206-17.

[11] Liu X, Liu G, Wang P, Huang Y, Liu E, Li D, et al. Prevalence of congenital heart disease and its related risk indicators among 90796 Chinese infants aged less than six months in Tianjin. Int J Epidemiol. 2015;( June):884-93.

[12] Cao H, Wei X, Guo X, Song C, Luo Y, Cui Y, et al. Screening high-risk clusters for developing congenital disabilities in mothers in Shanxi Province, China?: application of latent class cluster analysis. BMC Pregnancy Childbirth [Internet]. 2015;(56):1-9. Available from: http://dx.doi.org/10.1186/s12884015-0783-x 